\title{
E1 socialismo argentino frente a Enrico Ferri
}

\author{
Carlos Miguel Herrera \\ Universidad de Cergy-Pontoise \\ Carlos.Herrera@u-cergy.fr
}

La relación de Enrico Ferri (1856-1929) con el socialismo argentino ha quedado reducida a la polémica que lo enfrentara con Juan B. Justo sobre la razón de ser de un partido socialista en un país rural, al punto que sólo se ha insistido mayormente en su primer viaje, de julio a octubre de 1908 -algunos trabajos historiográficos parecen hasta ignorar la existencia de una segunda visita, acaecida poco después del Centenario (Crovetto, 1988)-. Incluso, la célebre controversia con Justo se redujo al análisis de textos, sin detenerse siquiera en sus circunstancias históricas. ${ }^{1}$

Los viajes de Ferri se desarrollan en un contexto de transformaciones para el país, tanto en el plano social como político. Buena parte de su "éxito" puede explicarse por una posición, la suya, que permite canalizar las preocupaciones que atraviesan las elites burguesas más avanzadas de la época en torno a la cuestión social. Y el visitante no se priva de enlazar en sus intervenciones tres problemas: la cuestión social, la nueva concepción jurídica y finalmente, el proyecto socialista, una trama que ya habia aparecido en su libro de 1894, Socialismo $e$ scienza positiva. ${ }^{2}$ Su propio perfil, como dirigente socialista y profesor universitario, facilitaba la articulación de un discurso complejo, pero donde se adivinan ya las fallas y tensiones que estallarán en su propia biografia a fines de la década.

Este trabajo retoma el análisis de su disputa con el socialismo argentino. No se trata tan sólo de ofrecer una mejor reconstrucción de su contexto: la polémica revela dos aspectos que superan la controversia

1. Como en otros temas de la historia del PS, parte de este reduccionismo se debió a la propia actitud del partido, que hará una larga promoción de la respuesta de Justo, al punto de incluir el texto de Ferri en las obras completas de aquél.

2. La obra había conocido dos ediciones en español.

(Archivos, año III, $\mathrm{n}^{\circ}$ 6, pp. 73-93) 
y sus entretelones. Por un lado, la evolución de las ideas de Ferri -y de una franja importante del socialismo europeo- hacia posturas nacionales y reformistas; de algún modo, sus posiciones en Argentina son reveladoras de su propia evolución política. Por el otro, la reacción del socialismo argentino, menos homogénea de lo que ha podido creerse, deja al descubierto las tensiones que están atravesando al PS en un momento clave de su historia, y que la aplicación de la ley Sáenz Peña terminará consolidando en una dirección precisa.

\section{El primer viaje de Ferri o la razón de ser del socialismo argentino}

Ferri desembarca en Buenos Aires el 18 de julio de 1908. El entusiasmo que rodea su llegada trasciende su afiliación socialista, y las iniciativas para agasajarlo son numerosas, en particular en los círculos intelectuales y juveniles. El diputado italiano es visto ante todo como un agente de la cultura europea e italiana, un "sabio", presentado la más de las veces como un "eminente sociólogo", portador de los últimos desarrollos del conocimiento social. Latinidad y ciencia son las principales coordenadas de su derrotero antes que su identidad partidaria.

El socialismo argentino, empero, no podía menos que participar y fomentar ese entusiasmo, ya que se trataba del primer dirigente socialista europeo de renombre que visitaba estas tierras. ${ }^{3}$ La Vanguardia acogía al viajero con una prometeica semblanza de su vida en su portada, ilustrada no sólo por su fotografia -un tanto antigua- en gran tamaño, sino también con las imágenes de sus tres hijos. Casi todos los miembros del Comité Ejecutivo se hacen presentes en el puerto y Antonio de Tomaso, promisorio dirigente, logra franquearse un lugar entre la multitud y hace uso de la palabra de manera improvisada para homenajearlo públicamente, recordando que muchos socialistas argentinos habían aprendido las nociones elementales de la doctrina en su ya citado Socialismo y ciencia positiva. ${ }^{4}$

3. Ferri había sido diputado desde 1886 , electo primero por agrupaciones radicales, y luego por el socialismo, función que conservará durante 9 legislaturas. Tras adherir al recientemente unificado Partito Socialista, en 1893, se transforma en uno de los jefes del ala revolucionaria enfrentada a Filippo Turati en la primera década del siglo XX. Se convierte así en secretario general en 1904 aliado con los sindicalistas. Ya un año antes había ocupado la dirección del órgano oficial del PSI, Avanti! Derrotado, a principios de 1908 abandona también la dirección del periódico (Sircana, 1997; Salvadori, 1960).

4. Ferri recordará más tarde que conocía al socialismo argentino por intermedio de Manuel Ugarte, y estaba en contacto epistolar con Alfredo Palacios en las inmediaciones de su viaje. 
Con todo, parecía claro que el propósito del viaje no era militante, y el propio Ferri recordará, en el discurso que dará origen al incidente público con Justo, que había advertido por carta a los dirigentes del PS, y reafirmado en sus primeros contactos personales, que no venía en plan socialista sino a asegurar el sustento para su familia, tras 15 años consagrados a la acción. En efecto, había sido contratado, como lo serán poco después Anatole France, Georges Clemenceau o aún Jean Jaurès, por un empresario teatral para dar 8 conferencias en el Teatro Odeón. ${ }^{5}$ Ferri prefería definir su propósito en el Plata como una obra de "vulgarización científica". La propia nota de La Vanguardia subrayaba en la presentación del "compañero" y "luchador esforzado", su calidad de "hombre de ciencias", de "sociólogo admirable". En cambio, Ferri parecía mostrarse abierto a otras invitaciones más militantes una vez terminados sus compromisos contractuales.

Rápidamente, la elite gobernante y universitaria aparece como su principal interlocutor. Así, se hace presente en las redacciones de los principales periódicos, como El Diario del senador Laínez o La Nación. No quedan tampoco fuera de programa las instituciones ligadas a su quehacer profesional, como el Congreso, la Facultad de Derecho o aún la Penitenciaría nacional. El punto más alto de su vida social tendrá lugar el 6 de agosto, cuando sea recibido por el presidente de la República, José Figueroa Alcorta. En comparación, el trato personal con los socialistas parece más restringido, reducido a dos visitas a La Vanguardia ya avanzada su estadía, lo que le será reprochado amargamente por sus camaradas cuando se produzca el cruce. Hasta entonces, las páginas del periódico se mostraban siempre generosas con el visitante, calificándolo de "sumamente simpático" en el primer contacto, dando luego amplia publicidad a sus conferencias, antes de glosarlas de manera entusiasta. Ferri, por su parte, se declaraba dispuesto a colaborar con el diario socialista, y se anuncian incluso una serie de conferencias "patrocinadas" por el partido entre el 8 y el 12 de octubre. Pero la promesa solo se concretaría al final de su viaje y se reducirá a una única actividad. ${ }^{6}$

Su primera conferencia en el Teatro Odeón tendrá lugar el 27 de

5. Sobre los viajes de estas figuras francesas, y en particular de Jaurès, ver Herrera (2009, 2014).

6. E. Quesada señalaba antes del choque de octubre que los socialistas estaban "algo sorprendidos y desconcertados" por la actitud de Ferri, pero que habian recibido como explicación la existencia de una cláusula contractual que le impedía participar en la agitación socialista, y se tranquilizaban con la promesa del conferencista italiano de prolongar su estadía para colaborar con ellos (Quesada, 1908). 
julio $^{7}$ y según los diarios de la época será un gran éxito. ${ }^{8}$ Ya antes de concluir su programa inicial, había comenzado a ofrecer una serie de charlas "extraordinarias" fuera de abono, siempre en el mismo escenario porteño, lo que era índice de su suceso. Era sólo un comienzo de una maratón oratoria: Ferri pronunciará más de 50 conferencias durante esos tres meses. Por cierto, no variará sólo las materias, sino también los lugares (Montevideo, Junín, Mercedes, Pergamino, Rosario, Santa Fe, Paraná, Córdoba, Tucumán...). Si ofrece siempre disertaciones sobre temas amplios, y un tanto fantasiosos (Wagner, los grandes navegantes, el espiritismo, etc.), no descuida por completo su campo y dedica una conferencia, que él mismo califica de "científica" para distinguirlas de las otras, en la Facultad de Derecho de Buenos Aires sobre la legislación penal argentina, donde llama al Gobierno a abolir la pena de muerte. No es de extrañar que Ernesto Quesada lo juzgue duramente desde el punto de vista científico, denostando su poca originalidad o un saber detenido "un cuarto de siglo atrás" aún en cuestiones de sociología.

El cierre del periplo discursivo de Ferri coincide con el fin de su estadía. Pero es allí, paradójicamente, cuando se produce su giro, ya que 48 horas antes de su partida tendrá lugar su presentación a beneficio de La Vanguardia, el órgano socialista. ${ }^{9} \mathrm{El}$ tema anunciado era "Qué es y cómo se realizará el socialismo". ${ }^{10}$

\section{La controversia}

En verdad, un primer contacto público con los socialistas había tenido lugar en un marco más amplio: el banquete que "la juventud estudiosa" le ofrece a Ferri el 11 de agosto. En esa ocasión, A. Palacios hará uso

7. En un texto publicado mucho más tarde, Rodolfo Rivarola, que lo presenta ante el público, señalará que había sido requerido por Ferri para evitar ser introducido por sus amigos socialistas. Rivarola deja entender que aquél quería mantenerse alejado de manera expresa de sus camaradas, lo que terminó generando la animosidad de éstos, y fue esta actitud lo que llevó a Ferri a hacer pública su hostilidad en su discurso del Teatro Victoria. El relato daría cuenta de cierto estado de ánimo de parte del criminalista italiano.

8. Según La Vanguardia, el público está formado por proletarios, profesores, médicos y abogados. Y al final del discurso un grupo viva al Ferri socialista, a la Internacional obrera y a los partidos socialistas argentino e italiano.

9. Según el relato posterior de los socialistas, fue Ferri quien tomó la iniciativa de la proposición, en un momento en que sus camaradas ya se mostraban desilusionados por su actitud. Aunque buena parte de su atención estaba ocupada en las elecciones a diputado por la Capital Federal del 18 de octubre.

10. Los precios de las entradas para la conferencia "a total beneficio de La Vanguardia", iban de 7,50 a 0,40 pesos, agotándose rápidamente. Había ese día 3.000 personas presentes según el diario socialista. 
de la palabra y en la mesa de honor se encuentran J.B. Justo, Nicolás Repetto y Enrique Dickmann. Ferri había tenido también ocasión de tratar a Enrique del Valle Iberlucea, en particular cuando la Universidad de La Plata, de la que éste era secretario general, le concederá el título de doctor honoris causa.

Es justamente del Valle Iberlucea quien lo introduce ante un auditorio socialista expectante que llena el Teatro Victoria -Ferri hará su elogio como así también el de Palacios y de Justo, cuando tome la palabra-. En su primer momento, el diputado italiano expone algunas ideas generales, extraídas de su célebre libro. Al final de su discurso, empero, desarrolla un conjunto de tesis que cuestionaban, de manera explicita, la razón de ser de un partido socialista en un país de débil industrialización como la Argentina. ${ }^{11}$ Ferri anotaba, al mismo tiempo, la ausencia en estas tierras de un auténtico partido radical que conformara su programa en torno a reivindicaciones democráticas, lo que obligaba al PS a asumir un conjunto de demandas institucionales. En los hechos, el programa del socialismo argentino era mixto: "obrero" o trade-unionista (es decir asumía un conjunto de demandas de los trabajadores, como la limitación de la jornada legal de trabajo) y "radical" en lo político (un plan de reformas basado en la extensión de la libertad política y de los principios del parlamentarismo). Lo que no hacia más que corroborar el hecho de que sin propiedad colectiva no podia haber doctrina socialista, y que el país no había alcanzado aún al grado de desarrollo económico para tener un partido socialista.

Los términos de la polémica, tal como se reconstruyeron posteriormente, son conocidos y sólo nos detendremos aquí en algunos detalles. Cabe precisar, ante todo, que los textos canonizados de la contienda son en realidad comentarios, meta-discursos, tras el intercambio público que había tenido lugar en la noche del 26 de octubre, publicados en la recién creada Revista Socialista Internacional dos meses más tarde y con Ferri ya en Italia -la versión original en italiano sigue a la traducción española-. ${ }^{12}$ Ferri asume más directamente que Justo el carácter posterior de su contribución escrita, proponiendo una historia de sus contactos con los socialistas argentinos y justificando sus propósitos. No se priva incluso de corregir una afirmación lanzada oralmente por Justo sobre Nueva Zelandia, aclarando que allí existe sólo un partido

11. Ya en su primer contacto con La Vanguardia, Ferri había subrayado que la Argentina se encontraba en un estadio de agricultura y pastoreo y "las manifestaciones sociales son paralelas a esta face [sic]". Por consiguiente, proseguía, "científicamente no se puede juzgar las condiciones de este país con la misma medida con que se juzgan los países de la civilización europea".

12. La Vanguardia retoma, en dos números sucesivos, ambos textos, antes de que sean publicados como folleto independiente. 
obrero, y no socialista, siendo este una forma evolucionada del primero. ${ }^{13}$ Pero el texto, que es redactado en momentos previos a su partida (está fechado el 29 de octubre), es una simple nota, poco elaborada, contrariamente al artículo de Justo, con sus referencias más sólidas, en particular de Marx.

La reacción pública de Justo -"vehemente" según La Argentina- fue más corta y menos estructurada, ${ }^{14}$ aunque estaba advertido de la visión del diputado italiano sobre el socialismo argentino como "flor exótica" desde el primer contacto personal, el día mismo de su llegada. Pero ya en su réplica oral, Justo juzgaba que Ferri mostraba un apego exagerado a la doctrina, ignorando la importancia del método para la ciencia. $\mathrm{Si}$, por caso, la socialización de los medios de producción era una necesidad para el socialismo, sus modalidades no podian conocerse de antemano, por ende, se debía evitar convertir las hipótesis en mitos o dogmas. Lo esencial del socialismo científico era su método, aplicable en cada lugar del globo donde hubiere explotación, trayendo el ejemplo de la Nueva Zelandia en lo que hacía a la evolución de la propiedad agrícola por intervención del Estado. Justo terminaba su corta réplica diciendo que el político Ferri debería indicar qué debía hacer la clase trabajadora con sus derechos políticos y qué nombre debía llevar el partido que ella forme, si es que consideraba necesario formar alguno.

Al retomar la palabra, Ferri evocará el rol del PS en términos de "suplencia cerebral", fenómeno neurológico observado en algunos pacientes, por el cual algunas circunvoluciones cerebrales sustituian en el trabajo psíquico funciones específicas de otras circunvoluciones, desaparecidas o enfermas. El socialismo desempeñaría así una función de "suplencia" en la política argentina, ante la inexistencia de partidos orgánicos, y sobre todo de un partido radical. Más tarde, tras la evolución de la propiedad individual, el socialismo podía encontrar su programa, acorde a su verdadero ideal. ${ }^{15}$

El PS ya había afrontado un cuestionamiento similar de parte de socialistas italianos en momentos en que se constituía oficialmente como partido. A finales de 1896 Angelo Monti sostenía, ante el entusiasmo mostrado por sus camaradas por la organización del PS, que faltaban las condiciones necesarias para el desarrollo del socialismo, ante la falta de gran industria. Otros militantes contradecirán a Monti. En su

13. Justo lo corregirá en su respuesta, diciendo que el nombre del partido es progresista...

14. N. Repetto, en sus memorias, hace pasar la respuesta escrita de Justo por la réplica oral que le dirigiera en el Teatro Victoria ...

15. Terminaba diciendo que el tiempo dirá quién de los dos contendientes tenía razón. La Nación, 27 de octubre de 1908. 
corta réplica, La Vanguardia insistía en el desarrollo de maquinaria en el campo, y admite que su programa, que va de las reformas más modestas hasta las aspiraciones de bienestar de los trabajadores, es defendido en parte y otras partes del mundo por los partidos avanzados de la burguesía ¿Ferri conocía esta polémica en las páginas de Lotta di Classe?Lo que es claro es que el eco no era el mismo en 1908, proferidas por una figura ampliamente reconocida y con un partido sólidamente instalado en la vida política y gremial del país. ${ }^{16}$

Los socialistas se dan cuenta inmediatamente del peligro que aparejaba tal juicio, y en los días sucesivos se improvisa una contraofensiva. La primera expresión tiene lugar en un acto público organizado al día siguiente, del cual los diarios se harán especial eco. A. Palacios acusa a Ferri de haber preferido la compañía de los poderosos y de no haberlos acompañados en la reciente brega electoral. "Quisimos ver al coloso, al agitador valiente, y sólo encontramos a quien [...] resultó ser 'un humilde servidor de los acontecimientos". El ex diputado socialista proponía a su público dejarlo partir silenciosamente, sin hacerlo portador de saludo alguno al proletariado italiano. Y, sobre todo, llamaba a continuar "nuestra tarea de elevación material, intelectual y moral del proletariado argentino y de saneamiento del ambiente político".

Los medios se multiplican. El 28 de octubre, con el título "Nuestra suplencia", el editorial de La Vanguardia denuncia la ligereza con la que Ferri habría pronunciado su sentencia de muerte. Aunque el PS estaba obligado a cumplir una "doble función", que no existía en otros países, el diario se preguntaba en qué se diferenciaban el partido argentino y su homólogo italiano, incluso en sus proyectos legislativos -según Ferri, la acción legislativa de un Palacios no era distinta de la de un representante radical-. Una carta de Luis E. Recabarren pide que se exija a Ferri una reparación de sus errores antes de su partida. Al día siguiente, los artículos se multiplican sobre el "éxito de Ferri", detallando los ecos que habían tenido sus palabras en la prensa "oligárquica". Un corto suelto sobre "Industria y socialismo" buscaba desbaratar las bases empíricas sobre las que el visitante habia construido su argumentación, detallando el número de industrias que utilizaban maquinaria a vapor o eléctrica en el país y empleaban un gran número de obreros (curtiembres, industrias gráficas, carpinteria, textiles, fábricas de fósforos, alpargatas, cigarrillos, vidrio, fideos, cerveza pero también establecimientos mecánicos como Vasena o La Cantábrica, sin contar los frigoríficos o las compañías de ferrocarriles y tranvias). Se publican además una serie de telegramas de Uruguay, Rosario, etc., aprobando la contestación de Justo.

La contraofensiva del PS operaba en dos planos. El primero era po-

16. Debo esta referencia a Lucas Poy, que prepara un artículo sobre el tema. 
lítico; allí se atacaba a Ferri por los ecos de su intervención en los enemigos del PS con variadas armas, como publicar su carta de despedida al presidente Figueroa Alcorta, contrastar sus dichos con un Manifiesto del socialismo peninsular a los trabajadores italianos en Argentina de 1898, o aún proponer un análisis de su psicología "dualista" y adaptable. Esta estrategia era coronada por una nota del secretario general, Mario Bravo, fechada el 18 de noviembre, que buscaba poner en conocimiento del partido italiano, "a los fines que se encontrare conveniente", la actitud de "su" diputado durante la estadía en Argentina, considerada contraria a la acción socialista (la carta iba acompañada de recortes de periódicos para probar sus dichos). ${ }^{17}$ Más adelante, frente a la reacción de Ferri ante esos ataques continuados, se abre una suscripción para pagarle su conferencia y devolverle así el beneficio pecuniario que había podido procurar a La Vanguardia...

Los socialistas buscan apuntalar su posición recogiendo también la opinión de otros socialistas europeos, como Pablo Iglesias. En una carta publicada en la Revista Socialista Internacional, el líder socialista español afirma:

En todo pueblo donde haya proletarios -y en la Argentina los hay- tiene razón de ser el Partido Socialista; que los hombres del Partido Socialista Argentino hacen una excelente labor por la causa de la emancipación humana, y que juzgo un deber de cuantos socialistas de otros países visiten esa nación, mostrar su solidaridad con ellos, ayudándoles en la lucha que mantienen y juzgando como enemigos propios a todos los que los combaten.

El otro plano es teórico y busca establecer la falsedad doctrinaria de la relación entre desarrollo industrial y socialismo que planteaba el "sabio turista", como se lo llama ahora. Es sin duda su contendiente de aquella noche quien marcaba las coordenadas de la réplica teórica, en el texto elaborado y conciso que publica Justo a fines de 1908. Allí Justo reafirma la asimetría entre una sociedad moderna, "intimamente vinculada al mercado universal" como la Argentina, y la ausencia de partidos políticos orgánicos, modernos. Su respuesta se escinde así en dos direcciones. La primera, de teoría económica; sosteniéndose en una lectura de El capital de Marx y su teoría de la "colonización capitalista

17. Alli se denuncia que Ferri se cuidaba de hacer referencia a su identidad socialista (se habla de una "dualidad irritante"), su falta de colaboración para con la propaganda socialista priorizando su interés pecuniario (negándose a hablar en un acto organizado por el partido de cara a las elecciones de octubre), y otros detalles de su visita, como haberse descubierto ante una iglesia en Santa Fe... 
sistemática", separa el maquinismo de la existencia de un proletariado, que no es mero producto de aquel. La segunda, de corte político, subraya que el PS es "el único partido que existe" en Argentina. Justamente, "la parte más viva del marxismo [...] es la práctica de la lucha de clases", y en definitiva "el socialismo es la acción" (Justo, 1908).

Pero el texto de Justo no era la única respuesta en esa dirección, si bien su posición dentro del partido le confiere un lugar preeminente. La ya citada Revista Socialista Internacional, que ambicionaba ser el órgano teórico del PS, encabeza las acciones. Su editor, E. del Valle Iberlucea había estado muy cercano a Ferri durante la visita y hay como cierta desilusión en la inquina con la que se lo perseguirá tras la conferencia. Un primer artículo de Carlos N. Caminos buscaba contradecir la posición del jurista italiano desde su título, "Porvenir del socialismo en Argentina".

Quizás la tentativa más ambiciosa se deba al propio del Valle Iberlucea, en su trabajo "Industrialismo y socialismo en la Argentina". ${ }^{18}$ Tras apuntalar con sesudas estadísticas la realidad del desarrollo industrial en el país, que mostraban para él que en 1895 había un millón trecientos mil trabajadores sobre una población de poco más de cuatro millones de habitantes, Del Valle apuntaba que la lucha por el socialismo en los países de América implicaba mayor energía, en la medida que no había una cultura democrática acendrada como en Europa, que limitaba el caciquismo y la oligarquía. Pero el socialismo no era planta exótica "en ningún país donde la propiedad privada de los medios de producción y cambio sea la base del régimen social". Sin ignorar la centralidad del maquinismo en el desarrollo del movimiento obrero al desarrollar la teoría del valor de Marx (citando El capital en francés), Del Valle insiste en la importancia de la acción política para la transformación del Estado, ya que éste es "el terreno de la lucha de clases". El bienestar de la clase obrera, obtenido por sus representantes en el parlamento a través de leyes, no hace más que reforzar la conciencia de su fuerza y su disposición a la lucha. En todo caso la expansión del capitalismo en todo el país "ha provocado" la emergencia del PS, que buscaba contener la dominación capitalista.

Su programa constituía la tercera parte del escrito, la única completamente original. ${ }^{19}$ Para Del Valle la apropiación individual de todo el suelo del país, aunque hubiese grandes tierras sin explotar, justifican

18. Se trataba, a la base, como el propio del Valle Iberlucea lo aclara, de un texto que ya habia publicado en las Anales de la Facultad de Derecho, y que él mismo habria dado a Ferri el dia de su llegada para contrarrestar sus opiniones sobre la ausencia de industrialismo en Argentina. Actualizado y con una tercera parte inédita, el estudio comienza a publicarse en el $\mathrm{n}^{\circ} 2$ de la Revista Socialista Internacional en entregas.

19. Esta parte dedicada al Partido Socialista argentino tampoco se edita en el folleto independiente que del Valle Iberlucea publica en 1909. 
la constitución de un "partido obrero". Únicamente ese partido puede evitar que la clase rica esclavice a los trabajadores. Pero el PS no solo invocaba la existencia material de la clase obrera para actuar, sino también "los altos principios de equidad y justicia, desenvueltos en la consciencia humana en la lucha secular e incesante por el derecho". Si su aspiración era la sustitución del régimen capitalista, su programa inmediato tenía por fin el mejoramiento económico de los trabajadores, necesario para que puedan realizar esa transformación cuando el desarrollo de las fuerzas productivas lo permita. En ese sentido, el programa es también político, y no sólo económico, porque alli donde no existe un partido de clase, las reformas económicas son frágiles y de corto alcance, como lo probaba según él la experiencia australiana. Del Valle pasaba a detallar, o mejor aún a explicar, la razón de ser socialista -es decir, para facilitar el "desarrollo político de la clase obrera"- de reivindicaciones como el sufragio universal para ambos sexos, el mandato revocatorio, la iniciativa popular, la autonomía municipal, el juicio por jurados, la abolición de la pena de muerte, la igualdad jurídica entre personas de ambos sexos, la supresión de las diferencias entre hijos legítimos e ilegitimos, la ley de divorcio, la separación de la Iglesia y el Estado, etc. Otro tanto hará con el programa económico y en materia de legislación social, defendiendo una ley de protección contra los accidentes de trabajo en una perspectiva socialista. Por esta vía, las dicotomías de Ferri se mostraban menos concluyentes, aunque Del Valle hablaba de "partido obrero" y de "partido socialista" sin distingos.

Por cierto, Ferri, que no pasará a la historia del socialismo italiano como un dirigente de alto vuelo doctrinal sino más bien por su habilidad política (que confinaba en ciertos casos con el oportunismo), no profundizará sus dichos. ${ }^{20}$ Pero los ecos de la polémica superan los círculos socialistas. La gran prensa porteña elogiaba la valentía de Ferri:

La prueba está en la forma franca y sincera con que el gran tribuno ha expuesto lo que piensa sobre el llamado socialismo argentino. Como se ve, nada lo intimida. Es consecuente con sus ideas. Sus palabras no pueden traicionar su pensamiento. ${ }^{21}$

Más tarde, la novel ciencia política argentina recogerá sus juicios para determinar la naturaleza del socialismo argentino y, llegado el caso, negar la pertinencia de su accionar.

20. En efecto, si había sido un intelectual avezado para la época en sociología y derecho penal, sus cualidades como teórico del socialismo no pasan del propagandismo, y su militancia se caracterizaba por los giros tácticos de sus opiniones políticas.

21. La Prensa, 29 de octubre de 1908. 


\section{El segundo viaje de Ferri o los confines del socialismo parlamentario}

Al despedirse, Ferri había hecho la promesa de volver en dos años y el 30 de julio de 1910 esta se materializa. ${ }^{22}$ Esta vez parece haber un cambio de perspectiva: ya no viene contratado por un empresario teatral sino invitado por la Facultad de Derecho, aunque los socialistas denunciarán que el impulso venía dado por el presidente Sáenz Peña en persona, al no poder confiar a Ferri una función oficial, como se habría comprometido al ser electo, por la oposición de sus aliados católicos. El sentido de su viaje cambia de todos modos y es ante todo el académico que pisa por esta vez el suelo argentino. Empero, terminadas sus obligaciones universitarias, no podrá sustraerse a una serie de cuatro conferencias en el Odeón. Pero a diferencia de su primera gira, no hay ahora temas fantasiosos, y entre esas charlas y las lecciones universitarias tampoco existe un abismo temático -la primera conferencia versa sobre "el actual movimiento social y político en la República Argentina"-. De hecho, la invitación a dar ese ciclo de conferencias en un teatro provenía de algunos de los oyentes de la cátedra, como J.V. González, R. Rivarola, A. Dellepiane o A. Álvarez, que le proponen hacer públicas sus "insinuaciones sobre hechos de la vida política y social de este país" en una carta que recoge la prensa.

El recibimiento de los socialistas está marcado por el silencio, pero circunstancias particulares contribuyen a ello: La Vanguardia, cuyos talleres y redacción habian sido destruidos por hordas nacionalistas en mayo, no está en la calle en momentos de su llegada, que se viven bajo estado de sitio. Y cuando vuelve a aparecer, el 16 de agosto, lo ignora, prefiriendo concentrarse en la visita de Adolfo Posada (que se muestra muy interesado por la obra del PS) o aún en las conferencias de Clemenceau. La indiferencia no dura mucho, y pronto se lo ataca sobre la cuestión de la doble ciudadanía, que ahora Ferri rechazaba, aunque La Vanguardia acepta la publicación de su carta de respuesta. Justo, por su parte, viajaba en esos momentos a Europa para participar como delegado en el congreso de la Internacional, en Copenhague.

22. Ferri permanecerá casi tres meses, zarpando de regreso el 24 de octubre. Tras sus conferencias porteñas, visitará varias localidades del interior y, sobre todo, recorrerá el Río Negro desde Viedma hasta Neuquén, una región que, como lo había anunciado a su llegada, le interesaba conocer. Dicho viaje alentará la posterior denuncia de los socialistas, que afirmaban que el profesor italiano habia recibido tierras fiscales sobre la línea ferroviaria de Neuquén. Se afirma incluso que una estación de dicha línea llevará su nombre (Repetto, 1955). El rumor existía y Ferri, a su llegada, busca descartar todo interés "especulativo", situándolo en la importancia de encontrar otras tierras para la inmigración italiana. 
Si se compara la crónica periodística, la segunda estadía del político italiano no despierta la misma curiosidad por su personalidad, lo que parece natural. Sin embargo, ya familiar del público argentino (escribía de tanto en tanto para La Nación), era interrogado por los periodistas a su llegada sobre su evolución política y su posición favorable a la participación del Partido Socialista en el gobierno italiano. Ferri desmiente que tras esa postura se esconda la ambición personal de ser ministro. Justifica su cambio de línea en el hecho de que el PSI era ahora un partido robusto, sólido, que podía llevar sus reivindicaciones a la política gubernamental. El carácter monárquico del Estado no era óbice para impedirlo, amparándose en la autoridad de Bebel, la gran figura del socialismo alemán y la Internacional.

El socialismo es un gran partido de orden, que ha metodizado y encauzado muchos elementos de orden y anarquía, que ha apaciguado y normalizado la vida italiana, haciendo oír la voz de los grandes intereses que, cuando son ahogados, allí como en cualquier parte, estallan en formas odiosas y que ponen en peligro la existencia social. Debe gobernar allí donde ha podido y sabido salvar. ${ }^{23}$

Ferri no perdía el carácter sulfuroso de su identidad política y un primer incidente ligado a ella estalla rápidamente: las autoridades de la Universidad de Córdoba se niegan a invitarlo a dar un curso, como lo había pedido el Centro de estudiantes. Finalmente, ante el repudio de la prensa capitalina, habrá un cambio de opinión, aunque resulta demasiado tardío para que Ferri acepte la invitación.

Pero el principal escándalo estallará en la citada conferencia pública del Odeón, el sábado 10 de septiembre, y será provocado por los socialistas. Ante un público menos numeroso, según la prensa, que el concitado dos años antes, Ferri disertaba sobre el movimiento político argentino. Anotaba en ese sentido un "síntoma" novedoso: la creación de nuevos partidos, que formulaban programas en torno a ideas y que respondian a determinados intereses sociales, lo que alejaba la politica de los personalismos. Veía como ejemplos la Unión Nacional creada en torno a R. Sáenz Peña o la Liga del Sur de Lisandro de la Torre. Recostándose en un artículo de José Ingenieros, Ferri imagina un sistema representativo de gobierno a la inglesa, con tres partidos defendiendo

23. La Nación, 31 de julio de 1910. Volverá sobre el tema al dar la última conferencia en Buenos Aires, el 19 de octubre, donde insiste en que el socialismo tiene que ver evolucionar su táctica, aunque subraya que debe ir al gobierno como partido, en representación de su credo y no encarnado por algunas personalidades. 
intereses económicos diversos, incluyendo un partido del trabajo, en defensa de los trabajadores.

Algunos gritos desde el palco habian ocasionalmente seguido sus palabras, pero ahora era interrumpido por E. Dickmann desde la platea, al que se suma otro viejo conocido, A. de Tomaso, que pide hablar cinco minutos. Ferri logra calmarlos con la promesa de escucharlos tras finalizar su propio discurso, lo que efectivamente ocurre. Desde el escenario, pese a los silbidos e interrupciones que van en aumento, de Tomaso reprocha al jurista italiano no haber hecho mención del PS entre los indicios que según él mostraban una tendencia hacia una vida política y social superior en la Argentina. Ferri responderá que su punto de vista no había variado: el socialismo no estaba "en su ambiente" y seguía sin entender su función en este país, donde hacía falta en realidad un partido obrero. Se declaraba empero de acuerdo con la obra que venía realizando el PS: lo que negaba era la eficacia de los criterios socialistas trasplantados de Europa. Cuando de Tomaso se disponía a replicar, se produce un nuevo incidente, cuando Dickmann, aparentemente fuera de sí, sube al escenario a los gritos, pero Ferri decide dejar el escenario, aplaudido por el público.

Los socialistas argentinos no se conforman y al dia siguiente lo desafian a una controversia pública sobre "1) el Partido socialista y el movimiento obrero, 2) el socialismo en la República Argentina”, proponiendo tres condiciones formales: que se haga un domingo por la tarde en un teatro, para que puedan asistir los obreros; que se nombre un presidente para dirigir los debates; que no se pueda salir del temario preestablecido. Ese mismo día, Ferri en una carta a La Vanguardia, aclara que fue su intervención la que permitió que el público escuchara al "joven" de Tomaso, y que se retiró porque el "otro señor", en lugar de discutir, injuriaba, pero sin hacerlo precipitadamente como lo reseñaba la crónica, alegando luego su falta de tiempo para asistir a la disputa a la que se lo invitaba.

El periódico rechazará sus argumentos, insistiendo que era un deber para el diputado italiano aceptarla. Se agrega a la polémica una misiva de De Tomaso precisando que el tumulto le había impedido responder una segunda vez a Ferri. Transcribia luego el texto de un artículo enviado dos meses atrás a La Nación (y que esta no había publicado pretextando el estado de sitio) donde juzga artificial el distingo entre partido socialista y partido obrero que hacía Ferri. El socialismo era más que una hipótesis económica o que una organización social, es un movimiento colectivo de elevación humana que se inscribe en la evolución histórica. ${ }^{24}$ Con respecto al argumento de la necesidad de propiedad privada

24. Martín Casaretto respondería a de Tomaso que no hay socialismo sin el propósito 
de toda la tierra, de Tomaso apunta que en un país de latifundios, la política agraria que libere al productor de la tiranía del propietario sería socialista ( $L V, 12-13$ de septiembre de 1910). También Dickmann publica una carta abierta a Ferri en el mismo número, donde denostaba su "vergonzosa fuga", apoyado por su "claque". No duda en calificarlo de "apóstata" y "traidor". En un tono particularmente violento, niega que haya sido socialista en algún momento de su vida, hablando de una mera "pose" alimentada por el escándalo y la demagogia. Pero también pone en tela de juicio su carácter de hombre de ciencia, y califica su última intervención de "conferencia servil".

Ferri escribirá nuevamente al diario para confirmar, tras otra carta, esta vez de Repetto, sus juicios sobre el PS. Aprovechaba ahora para denunciar la nota que en su momento mandara el partido argentino a su homólogo italiano y a la Internacional, y que no tuviera ningún efecto, porque las opiniones son libres. Ferri apuntaba contradicciones entre el accionar del PS en pos del problema obrero y su programa socialista, que también hallaba en la cuestión agraria. Llamaba una vez más a los socialistas argentinos a no copiar a los europeos y confiaba haber contribuido a orientarlos hacia la realidad positiva, de acuerdo con el ambiente americano.

Para los socialistas argentinos, la burguesía criolla había puesto en marcha una obra "socialisticida" de la que participa el diputado italiano (un discurso suyo en homenaje a Figueroa Alcorta en Mendoza era una prueba más). Las injurias terminarán con la partida de Ferri, calificado de "histrión", que al partir deja "un macilento cadáver, el de la vaca lechera de su ciencia, muerta tísica de tanto ordeñada"...

\section{Acción politica y acción socialista}

Aunque se decia socialista para toda la vida, Ferri afirmaba en su segunda carta a La Vanguardia que los partidos socialistas habian cumplido su rol al despertar al proletariado, darle una organización de clase y... estimular en la burguesía la conciencia de la importancia de la legislación. Pero la evolución los conducía, como en Francia o Italia, hacia partidos obreros que alentaban reformas prácticas. Ahora era Ferri quien parecía cambiar el foco de su visión y su argumento mostraba cierta circularidad.

Es quizás en las lecciones de la Facultad de Derecho que podemos encontrar la mejor concentración del pensamiento socialista de Ferri. ${ }^{25}$

final de la propiedad colectiva.

25. En todo caso, es la única ocasión, en sus dos viajes a Argentina, en que desarrollará sus ideas sociales con cierta sistematicidad. 
En 1910 se sigue definiendo como "socialista científico" y también "militante" pero su análisis sobre la cuestión obrera se afirma como el examen objetivo del sociólogo. Ferri situaba la cuestión de la justicia social en una doble coincidencia de intereses, la del obrero y el capitalista, y la de la Argentina y la inmigración, que era precedida de una constatación: no hay inmovilidad e invariabilidad, toda sociedad está en vias de continua formación. Su vieja tesis que veía las reformas en el campo del derecho, y en particular en el derecho penal, como reformas sociales, que se logran mejorando las condiciones del trabajo, era una ilustración de eso. De hecho, asevera que el legislador del futuro pedirá la norma al pedagogo y al psiquiatra. Pero la miseria, material o moral, no era la única causa del delito y es por eso que subsistirá siempre, aun en formas más elevadas de civilización. Más aún: el mejoramiento de la sociedad se produce por una evolución "lentísima", lo que explica que la justicia represiva sea siempre necesaria. Pero no podía ser la única forma, y en su modalidad actual no hacía más que aumentar el delito (su defecto, como insistirá siempre, es concentrarse en el delito y no en el delincuente). Pero la defensa de la sociedad contra aquellos que luchan por su existencia con el modo anormal del delito era sólo una parte de la tarea del Estado. La otra era "comprender y secundar" el desarrollo de la defensa social para la gran mayoria de la clase trabajadora, aquella que lucha por la existencia bajo formas normales.

En verdad, la justicia social para los trabajadores seguía dos vías paralelas, la de las propias organizaciones proletarias, a través de la solidaridad, y la del Estado, a través de la legislación social. Ferri desarrolla aquí una de las fuentes teóricas de su crítica al socialismo argentino. La clase obrera sólo surgía con la máquina a vapor porque ella obligaba a la reunión de grandes grupos de obreros en fábricas, propias del industrialismo moderno. Solo la máquina a vapor y los grandes establecimientos fabriles crean al proletariado como clase, porque permiten ese contacto directo y continuo entre sí que permitía desarrollar su conciencia de clase, y que le permitía incluso empujar consigo a otras fuerzas sociales menos dinámicas dentro del esquema industrial, como el campesinado. Sus esfuerzos actuales tendian al logro de la justicia social, y en ese sentido, el trabajo era una fuerza más que una mercancía. Porque toda organización obrera se desarrollaba entre dos leyes generales: la lucha de los intereses antagónicos y la solidaridad de los intereses iguales.

Así se reconstruía su esquema de la evolución social, que pasaba por la concatenación de tres fenómenos sucesivos: necesidad, interés, derecho. "El proletariado tiene, hoy y siempre, necesidades que se vuelven en consecuencia sus intereses; y lucha para que esos intereses revistan el aspecto y asuman las prerrogativas de derechos". El derecho, afirmaba sin gran originalidad, es una conquista. No hay derechos innatos, todos 
son adquiridos; incluso el derecho a la vida, el primero de los derechos, era desconocido en la esclavitud. La clase obrera luchaba por conquistar el derecho a la vida más completa. Otro tanto ocurría con el derecho de huelga, que se había convertido en uno de los vehículos más eficaces de la civilización, en países como Inglaterra.

Para Ferri, todas las clases sociales tenían derecho a mejorar sus condiciones, no existiendo más que un límite, aquel que contrapone el interés individual al interés social. Pero para los teóricos de la Revolución, el mejoramiento de la clase obrera sólo podía producirse por la violencia. Oponiéndose a Georges Sorel, el jurista italiano aseveraba que toda conquista futura se podría alcanzar con las vías de la razón, y la revolución no era necesariamente violenta. La jornada de 8 horas, un alojamiento salubre, la jubilación, la ley de accidentes de trabajo son de hecho revoluciones. En todo caso, no se podía imponer "por la violencia" una etapa nueva de la civilización si ese estadio no había sido "elaborado por las modificaciones graduales" de las condiciones donde "la nueva civilización deberá desenvolverse". En esta clave evolucionista, consideraba que el espíritu de revuelta no era un signo de fuerza sino representaba un estadio infantil del pueblo.

A su juicio, las dos fuerzas en lucha sabian hoy comprenderse y valorarse. La burguesía y el Estado parecian percibir el derecho del proletariado a condiciones de vida más humana, y el proletariado, por su parte, comprendía lo que aquellos podian concederle. En particular, el proletariado debía entender que su carácter mayoritario "no puede constituir el derecho a todos los derechos". Si la lucha de clases era un fenómeno real, inevitable, puede ser combatida con armas civiles. ${ }^{26}$

En ese sentido, detalla que los instrumentos con que cuenta la clase trabajadora eran principalmente el mutualismo, la resistencia y la cooperación. Los tres no podian ser separados, porque si el primero y el tercero proveian al proletario una existencia menos penosa, consolidando la victoria de la lucha, la elevación de la clase obrera implicaba conquistar siempre nuevas posiciones. Pero calificaba como formas anormales de resistencia el boicot, el obstruccionismo, el sabotaje e incluso la huelga -atacando una vez a Sorel en su idea de que la humanidad sería en un futuro completamente regulada por los sindicatos profesionales-.

Pero quedaba el otro aspecto, la legislación social, que, como Ferri señalaba, no debía ser confundida con la legislación laboral, que era sólo una parte de ella. A través de la legislación social, el Estado se interponía entre ambos litigantes, para mediar y pacificar. Las funciones de la legislación social eran tres: disminuir las dolencias del trabajo,

26. Ferri, claro, se dirige a las clases dirigentes: "La cuestión obrera es como la marea: se puede canalizarla pero no sofocarla". 
elevar el nivel de vida físico y moral de los trabajadores, desarrollar la tendencia a asociar el trabajo individual con el trabajo colectivo. ${ }^{27}$ Este programa, que debía ser adaptado por todas las naciones, había tenido para él su expresión en Argentina con el proyecto de Código de trabajo de J.V. González de 1904. Había un derecho nuevo, el derecho en devenir, el derecho que se adaptaba a las formas de la vida. El socialismo, con la crítica y con la acción positiva, desarrollaba la legislación del trabajo y creaba la jurisprudencia de un nuevo derecho. Ferri podía entonces concluir que "la legislación social no es más que la sanción del derecho madurado en el seno de las organizaciones obreras, derecho que surge de las condiciones del trabajo y de la civilización".

No costaba a Ferri asumir de manera explícita su cambio, dando fundamento teórico-político a su evolución. ${ }^{28}$ Si desde 1908 se mostraba favorable a la participación de los socialistas en el Gobierno para realizar las reformas que reivindica, asumiendo la responsabilidad del poder, era porque tenían ahora la fuerza y la práctica necesarias para hacerlo. Utilizaba en ese sentido una metáfora peculiar: "Por qué ser pasajero de un tren cuando se puede ser su maquinista y guiarlo" (Ferri, 1911). En ese punto, se tensaba una vez más la diferencia con el caso argentino: no sólo era imposible saltar a un partido socialista sin pasar por el partido obrero, sino que la propia evolución de aquellos les permitía ahora participar en el Gobierno, lo que situaba más lejos aún las "perspectivas" socialistas en el país.

Pero la posición de Ferri revelaba las propias tensiones dentro del Partido Socialista Argentino, y el carácter bifronte de su proyecto. Estas habian surgido ya en ocasión del choque de 1908, cuando una polémica soterrada apareció ante una circunstancia banal, la publicación de una extensa carta abierta a Justo de un socialista extranjero afincado en el país, Elías Leyboff. Las reacciones que producía dejaban al descubierto algo más que la ansiedad que atravesaba al PS tras los dichos de Ferri, revelando la existencia incipiente de tres corrientes internas, que pocos

27. Para él, las leyes sociales del trabajo eran la estadística del trabajo y la reglamentación del trabajo (higiene, reposo dominical, la prohibición del trabajo nocturno, la inspección del trabajo), pero también apuntaba la importancia del contrato colectivo, de las oficinas de colocación, de los seguros de accidente de trabajo, de protección de la vejez, o aún contra la desocupación. Entre la legislación social que no se refería al trabajo, Ferri destacaba la instrucción obligatoria, la vivienda obrera, pero también las leyes fiscales.

28. Ferri termina alejándose del PSI poco después de su regreso del segundo viaje a Argentina, ubicándose como "socialista independiente", cercano al reformismo de derecha. Tras finalizar la Primera Guerra Mundial, vuelve a ser electo diputado en 1921, y milita en el Partito Socialista Unitario. Pero termina acercándose a Mussolini, que lo nombra senador poco antes de morir (Sircana, 1997). 
años más tarde se tornarian explícitas y producirian sendas rupturas. Leyboff cuestionaba las ideas demasiado personales de Ferri en materia de doctrina socialista, pero no desaprobaba del todo sus observaciones sobre el PS argentino, poniendo en tela de juicio la lectura de Justo. Para este militante de origen ruso lo que caracterizaba al socialismo era su fin de socialización de los medios de producción, y la lucha de clases como medio. La propiedad colectiva no podía ser una mera hipótesis, sino que resultaba del propio desarrollo del capitalismo. Aprovechaba también para atacar la línea de La Vanguardia, que para él no inspiraba ideas socialistas. Si el PS existía, sólo estaba en sus comienzos y no debe convertirse en simple vanguardia de la burguesía. Y esto exige que la ideología socialista sea puesta en primera fila.

Tras la publicación de la carta en la Revista Socialista Internacional, Del Valle Iberlucea estimaba, desde una implícita posición de izquierda, que Leyboff incurria en errores de interpretación, como juzgar que la socialización de la propiedad era una simple hipótesis para los socialistas argentinos, lo que era una no menos abierta critica a Justo. Del Valle recordaba en ese sentido la importancia de la "Declaración de principios" que era su programa máximo, y cuya fuente era el marxismo, lo que afirmaba el carácter universal del socialismo argentino, que no correspondia a un supuesto modelo "a la americana". Y para evitar toda confusión entre partido del trabajo y partido socialista, recordaba que el gobierno encabezado por el Partido del Trabajo australiano acababa de reprimir una huelga y meter en la cárcel al líder socialista.

Justo, tras calificar de "ligeras" las objeciones (y sin afrontar directamente el fondo del debate), se contentaba con clarificar el sentido que daba a la palabra "hipótesis" cuando se refería al colectivismo en su respuesta a Ferri, es decir como "previsión no confirmada aún por la experiencia". Empero, la hipótesis del colectivismo conducía a una gran acción cotidiana de la clase obrera para que sea probada, o al menos "levantar a la clase trabajadora a un nivel superior de vida material e intelectual, en el cual adquiera las fuerzas necesarias para su emancipación". Para Justo, en efecto, la fuerza del PS no le permitía ahora transformar radicalmente la sociedad por una revolución, ni siquiera era suficiente para imponer la verdad del sufragio o el cumplimiento de la legislación social.

De Tomaso, a su vez, interpretaba la respuesta de Justo como una convalidación del juicio reformista de Bernstein que había agitado las aguas del socialismo alemán, según el cual el movimiento era todo y el fin, nada. Apostrofando una vez más el dogmatismo de Ferri, atacaba también las definiciones dogmáticas de un Kautsky, marxista "ortodoxo" que dejaba de lado la importancia de la acción cotidiana y que había sido a su juicio derrotado. La doctrina debía ajustarse a los hechos y 
no había partido socialista "sin movimiento o acción socialista". Justo considerará necesario aclarar -tras una nueva carta de Leyboff donde reafirma que lo que interesa es la "orientación práctica"- que no hacía suya la frase de Bernstein, precisando que la agitación socialista se estribaba en una teoría de la historia -según la cual sin progreso técnico-económico no hay progreso histórico posible-, permitiéndole una acción encaminada y consciente. La diferencia no era de doctrina sino de método, defendiendo la acción electoral. ${ }^{29}$

No era de extrañar que tras el segundo viaje de Ferri, y la normalización de la vida partidaria, estas diferencias se tornasen más concretas. El IX Congreso del Partido, en diciembre de 1910, daba una nueva resonancia a la cuestión. El debate surgía sobre el balance de La Vanguardia, dirigida entonces por Justo, y su transformación en sociedad comercial comanditaria, pero sobre todo se le reclamaba una inspiración de clase. Como lo sintetizaba del Valle, la minoría "quería acercar más el partido a la vida de los trabajadores, sin desconocer su rol político, que no comprende, sin embargo, toda su misión" (Del Valle Iberlucea, 1911). Los opositores serán derrotados y Del Valle Iberlucea, que era su figura más prominente, declina integrar el nuevo Comité ejecutivo.

La respuesta de Justo ante esos reclamos había sido la promoción de agrupaciones socialistas de oficio que pudiesen adherir al partido directamente. La minoría se había opuesto, porque, como lo afirmaba M. Casaretto, se debia reforzar las organizaciones obreras, no el accionar político. Durante todo el año 1911, La Vanguardia había calificado la resolución como la más importante aprobada en el Congreso, insistirá ante sus lectores para avanzar en su materialización, que permitiria estimular a los trabajadores en la lucha política. Pero la prueba de que el IX Congreso no había logrado zanjar las diferencias era dada por el hecho de que sólo obreros gráficos habían constituido una agrupación socialista. Tampoco se logrará transformar al periódico en sociedad comercial. Es por ello que el X Congreso nacional, que tiene lugar en enero de 1912, será el teatro de la misma representación, ampliándose incluso la contestación. Pero la posición "centrista" de Del Valle Iberlucea se revelará insuficiente para contener a los sectores izquierdistas, lo que se hace más notable con su elección como senador de la Capital. ${ }^{30}$

$\mathrm{Si}$, como lo afirmaba E. Dickmann, otra bête noire de la minoría en

29. La Vanguardia, 18, 20, 22-23 de febrero de 1909. Habrá un último texto de De Tomaso, colocando su interpretación bajo la férula justista.

30. En julio de 1912 estos comienzan a editar Palabra Socialista, donde se encuentran en un primer momento los militantes cercanos a Del Valle, como Fernando de Andreis, y algunos dirigentes ligados al trabajo gremial como M. Casaretto o Pedro Zibecchi. E. Leyboff aparece como uno de sus teóricos de mayor calado con sus largos artículos, aunque no pertenece al grupo en sentido estricto. Del Valle Iberlucea no materializará 
el Congreso de 1910, "la lucha social debe ser aquí lucha política", las posiciones de Ferri revelaban lo que efectivamente estaba haciendo la dirección partidaria. En el fondo, se trató siempre de saber cuál debía ser el programa de ese partido socialista, y por ende, su tipo de acción. El mismo Dickmann, que no había dudado en interpelar a Ferri, era el primero en aseverar, contra aquellos que reclamaban un mayor anclaje obrero del PS, que no había un gran movimiento gremial porque la industria era aquí incipiente, y la lucha era menos contra la patronal que contra la oligarquía y el latifundio...

\section{Bibliografia}

Crovetto, P. (1988), "Enrico Ferri in Argentina", en F. Devoto y G. Rosoli (eds.), L'Italia nella società Argentina, Roma.

Del Valle Iberlucea, E. (1909), "Industrialismo y socialismo en la Argentina", Revista Socialista Internacional.

- (1911), "IX Congreso socialista", Humanidad Nueva.

Herrera, C.M. (2009), "Jaurès en la Argentina - La Argentina de Jaurès", Estudios Sociales, $\mathrm{n}^{\circ} 37$.

- (2014), "El político, el científico, lo social: las visitas de Jean Jaurès y Léon Duguit", en P. Bruno (ed.), Visitas culturales en Argentina entre 1910 y 1930, Buenos Aires: Biblios.

Ferri, E. (1908), "El Partido socialista argentino", Revista Socialista Internacional.

- (1911), Le conferenze di Enrico Ferri nella Repubblica Argentina, Buenos Aires: Buffarini,

Justo, J.B. (1908), "El profesor Ferri y el Partido Socialista Argentino", Revista Socialista Internacional.

Leyboff, E. (1909), "Carta abierta al ciudadano Justo", Revista Socialista Internacional

Quesada, E. (1908), "Ferri conferencista", Nosotros, t. III.

Repetto, N. (1955), Mi paso por la politica. De Roca a Yrigoyen, Buenos Aires: Rueda.

Sircana, G. (1997), "Enrico Ferri”, Dizionario biografico degli Italiani, vol. 47.

Salvadori, R. (1960), "Enrico Ferri politico. Dal radicalismo all'adesione al partito socialista", Rivista Storica del Socialismo, III.

$* * *$

su anunciada colaboración hasta 1913, con dos artículos sobre "La lucha de clases" y "El colectivismo" en el n 12 . Ver el artículo de Hernán Díaz en este dossier. 
Titulo: Argentine socialism in front of Enrico Ferri

Resumen: Las visitas del socialista italiano Enrico Ferri fueron la ocasión de fuertes debates en el socialismo argentino. Pero contrariamente a lo que se cree habitualmente, estos no se resumieron a la célebre respuesta de Juan B. Justo. No sólo otras voces participan de la discusión: estas dejan aparecer un conjunto de tensiones que terminarán traduciéndose en rupturas a partir de la Primera Guerra Mundial. Las posiciones de Ferri sobre el socialismo argentino, pero también su propia evolución dentro del socialismo italiano, aparecen como los sintomas de la crisis del socialismo parlamentario.

Palabras clave: Ferri - Justo - Socialismo argentino - Del Valle Iberlucea - Reformismo

Abstract: The visits of the Italian socialist Enrico Ferri were the occasion of intense debates in the Argentine socialism. But contrary to what is commonly thought, they are not summarized in the famous Juan B. Justo reply. Not only other voices involved in the dispute, but let appear a set of tensions that will end up producing a series of divisions from the First World War. Ferri's positions on the Argentine socialism, but also its evolution within the Italian socialism, appear as symptoms of the crisis of parliamentary socialism.

Keywords: Ferri - Justo - Argentine Socialism - Del Valle Iberlucea - Reformism

Recepción: 26 de enero de 2015. Aprobación: 28 de febrero de 2015. 